\title{
RESPONSABILIDADE SOCIOAMBIENTAL A PARTIR DA UTILIZAÇÃO E DESCARTE DE MEDICAMENTOS
}

Ronualdo Marques ${ }^{1}$

Claudia Regina Xavier²

Resumo: A Educação Ambiental contribui para formação de cidadãos críticos e ativos na preservação do Meio Ambiente. Este estudo exibe uma discussão sobre a percepção dos estudantes com o uso e descarte de medicamentos e ainda, o grau de informação a respeito de suas implicações em relação a saúde pública e/ou ao Meio Ambiente e assim sensibilizar, conscientizar e orientar para o correto destino final. O estudo foi desenvolvido em 2017, com 95 alunos, do Colégio Estadual Pedro Macedo em Curitiba - PR. Pôde-se concluir que a temática dos medicamentos contribui para a Responsabilidade socioambiental com o desenvolvimento de ações potencializando discussões que emergem das relações entre os seres humanos, sociedade e natureza.

Palavras-chave: Responsabilidade Socioambiental; Descarte de Medicamentos; Educação Ambiental; Medicamentos; Saúde. 


\section{Introdução}

A Educação Ambiental (EA) interfere em nossas vidas e discuti-la favorece a compreensão da realidade e a participação social. Jacobi (2003) destaca que a EA anseia por "uma nova forma de encarar a relação do homem com a natureza, baseada numa nova ética, que pressupõe outros valores morais e uma forma diferente de ver o mundo e os homens". Temos no uso e descarte incorreto de medicamentos um problema que deve ser discutido no âmbito escolar a fim de evitar impactos ambientais negativos.

Estima-se que existam mais de 60.000 compostos químicos em uso nas sociedades modernas e que cerca de 500 novos produtos químicos são colocados no mercado anualmente. A poluição ambiental tem acompanhado o avanço tecnológico e industrial. $O$ desenvolvimento de grandes centros urbanos levou à contaminação do ar, água e solo, como consequência da produção e uso de energia, produção e uso de substâncias químicas industriais e farmacêuticas e aumento da atividade agrícola (LIMA, 2003).

Sendo assim a Educação Ambiental como um processo contínuo e permanente, deve atingir todas as fases do ensino formal, não formal e informal; deve também examinar as questões ambientais do ponto de vista local, regional, nacional e até internacional, avaliando suas causas, consequências e sua complexidade (DIAS, 2004).

A transformação de materiais em produtos acabados e a prestação de serviços pelas empresas são atividades que geram resíduos. A união de um número cada vez maior de pessoas no planeta que consomem cada vez mais produtos e serviços tende a elevar de modo significativo a quantidade de lixo que é lançada ao meio ambiente todos os dias. Um tipo de resíduo que impacta fortemente na saúde pública e o meio ambiente é o descarte de medicamentos, que pode contaminar água e solo, que nos levam a seguinte reflexão: para onde vão tais substâncias?

Os medicamentos, ao serem descartados em locais inadequados, como vasos sanitários ou lavabos, se dissolvem formando uma mancha tóxica. Os descartados em lixos domésticos podem entrar em contato com outros seres humanos, contaminando-os, já no lixão, aterro controlado ou aterro sanitário são transformados em poluentes, ou seja, em uma substância tóxica, chamada chorume ou líquido percolado, que pode infectar ao mesmo tempo o solo, o lençol freático, os rios e a atmosfera.

Ambos, ao contaminarem a água, percorrem pela rede de esgotos da cidade até chegar a uma estação de tratamento, no caso de cidades que possuam esse serviço. A mancha tóxica de remédios não é tratada como o esgoto normal, pois a mesma necessita de um processo especial, que não ocorre na estação de tratamento. Da estação de tratamento, os resíduos farmacológicos não tratados, são liberados em rios, lagos e mares, agravando assim, a poluição no meio ambiente.

Tem-se que a aquisição de medicamentos pela população nas drogarias ou farmácias deve ser feita com as devidas orientações de um

revista brasileira educação ambiental 
médico. Nestes estabelecimentos é dever do farmacêutico realizar a dispensação correta, explicando a posologia dos medicamentos e esclarecendo dúvidas. O acúmulo de medicamentos nas residências incentiva a automedicação e o descarte inapropriado e, desta forma, configura risco à saúde e ao meio ambiente (GASPARINI; GASPARINI; FRIGIERI, 2011).

Com a evolução dos medicamentos, além das vantagens no combate às doenças existem os problemas advindos de sua fabricação e utilização. As sobras de tratamentos anteriores, ou mesmo a dispensação de medicamentos em quantidade superior ao tratamento devido e prescrição incompleta ou incorreta, juntamente com a impossibilidade de fracionamento de alguns desses produtos (EICKHOFF; HEINECK; SEIXAS, 2009), podem causar o seu acúmulo e posterior perda do prazo de validade.

A falta de informações quanto ao descarte correto dos medicamentos vencidos e/ou inutilizados pela população geram um descarte inadequado. Conforme Gasparini et al., (2011), o descarte inadequado é feito pela maioria das pessoas por falta de informação e divulgação sobre os danos causados pelos medicamentos ao meio ambiente e ainda por carência de postos de coleta.

A solução deste problema passa por uma Política de Educação Ambiental, com campanhas no ambiente escolar com amplitude para a população, elucidando a importância do descarte em locais adequados e o risco de não fazê-lo. Uma das medidas eficazes seria a adoção obrigatória em todo o país do fracionamento de medicamentos, em cuja embalagem irá constar apenas a quantidade correta para o tratamento, evitando possíveis sobras, assim a população poderá obter fármacos na quantidade ideal para 0 tratamento que deseja (BORRELY et al., 2012).

Tendo em vista a realidade do consumo de medicamentos em nosso país, a destinação final que é dada aos medicamentos e as consequências à saúde da população e ao meio ambiente, essa pesquisa tem por objetivo investigar qual a relação dos estudantes com os medicamentos e o grau de informação da população estudada a respeito do correto descarte de medicamentos e suas implicações em relação à saúde pública e/ou ao meio ambiente e a partir daí sugerir medidas na comunidade escolar a fim de sensibilizar, conscientizar e orientar o correto descarte de medicamentos.

Com o intuito de promover uma ação coletiva entre fabricantes, é discutida constantemente a logística reversa, um assunto de grande importância para medidas que preveem o destino final dos medicamentos coletados. A logística reversa tem como objetivo em todo território nacional a adoção do correto descarte de medicamentos e da reutilização (que necessita de estudos aprofundados), medida que visa à diminuição de medicamentos descartados de forma indevida, estimulando o consumo sustentável a fim de reduzir os impactos ambientais. Esta medida está incluída na Política Nacional de Resíduos Sólidos (SEMINÁRIO, 2012). 
Hoje no Brasil existe uma grande diversidade de regulamentações e iniciativas nos estados e municípios de recolhimento, devolução, doação e descarte de resíduos de medicamentos pela população. Isso se deve ao fato de ainda não se ter uma regulamentação específica no âmbito nacional relacionada ao descarte e destinação final ambientalmente adequada de resíduos de medicamentos descartados pela população.

A Resolução ํo 358, de 29 de abril de 2005 do CONAMA dispõem sobre o gerenciamento dos resíduos desde a geração até o seu descarte final, de forma a atender aos requisitos ambientais e de saúde pública e saúde ocupacional, sem prejuízo de responsabilização solidária de todos aqueles, pessoas físicas e jurídicas que, direta ou indiretamente, causem ou possam causar degradação ambiental.

A Agência Nacional de Vigilância Sanitária (ANVISA), por sua vez, utiliza-se da Lei no 12.305, de 2 de agosto de 2010, que institui a Política Nacional de Resíduos Sólidos, com a finalidade de preservar a saúde pública e proteger e melhorar a qualidade do meio ambiente. Esta lei, também, torna-se integrante da Política Nacional do Meio Ambiente e articula-se com a Política Nacional de Educação Ambiental, regulada pela Lei no 9.795, de 27 de abril de 1999, com a Política Federal de Saneamento Básico, regulada pela Lei no 11.445, de 2007, e com a Lei no 11.107, de 6 de abril de 2005 que aborda sobre o tratamento e à disposição final dos resíduos dos serviços de saúde (BRASIL, 2010).

O Ministério da Saúde e o Ministério do Meio Ambiente tratam dos resíduos sólidos de origem farmacêutica. Os órgãos de vigilância sanitária e ambiental são responsáveis pelos instrumentos legais, pelo fomento de pesquisas e pela fiscalização, para garantir que as atividades geradoras de resíduos dessa natureza lhes deem a destinação adequada (FALQUETO; KLIGERMAN; ASSUMPÇÃO, 2010). Esses órgãos possuem o mesmo objetivo, que é a preservação da saúde pública e ambiental através de medidas de controle dos medicamentos oferecidos à população.

Os principais agentes que geram resíduos de medicamentos são as indústrias farmacêuticas e, distribuidores, farmácias, drogarias e hospitais. As indústrias farmacêuticas são geradoras de uma quantidade considerável de resíduos sólidos devido à devolução e ao recolhimento de medicamentos do mercado, ao descarte de medicamentos rejeitados pelo controle de qualidade e perdas inerentes ao processo (FALQUETO et al., 2010).

Os distribuidores, farmácias, drogarias e hospitais se enquadram em regulamentos técnicos descritos pela Agência Nacional de Vigilância Sanitária (ANVISA) e Conama, que consideram que estes atores são geradores de resíduos de serviços de saúde de todos os serviços relacionados com o atendimento à saúde humana ou animal, drogarias e farmácias de manipulação e distribuidores de produtos farmacêuticos. Assim, eles devem elaborar o Plano de Gerenciamento de Resíduos de Serviços de Saúde (PGRSS), a ser feito por profissional registrado no conselho da classe (FALQUETO et al., 2010).

revista brasileira educação ambiental 
Contudo esses estabelecimentos comerciais como farmácias, drogarias e centros de saúde não são obrigados por lei a recolher medicamentos (UEDA et al., 2009).

No entanto de acordo com Aligleri (2009) observa-se atualmente um cenário em que as empresas "necessitam aceitar e comprometer-se com as consequências e impactos de suas decisões e ações, além de responder as demandas de todos os afetados pelas suas atividades" (ALIGLERI, 2009, p. 9).

Como forma de contextualizar as ações em um espaço escolar, foi desenvolvido e aplicado um Projeto de Ação na Escola para fomentar o processo de Educação Ambiental a partir da responsabilidade social discutindo a problemática socioambiental do descarte de medicamentos de forma incorreta e promovendo uma campanha com o recolhimento de medicamentos vencidos para a destinação em postos que realizam adequadamente a deposição final destes.

A responsabilidade socioambiental vem ganhando espaço nas discussões mundiais, devido à maior conscientização tanto pela sociedade quanto pelas empresas. Essas últimas consideram a responsabilidade social somada a sua atuação econômica (GARCIA, 2002).

Dessa forma, a responsabilidade socioambiental deve ocorrer desde as empresas que fazem a venda de medicamentos ficando responsabilizadas pelo seu recolhimento e a conscientização da população para o descarte correto dos mesmos. Segundo Alvarenga e Nicoletti,

A população tem sua parcela de responsabilidade no processo devendo estar esclarecida e envolvida no processo de conscientização da geração de resíduos bem como da importância do uso racional de medicamentos como sendo uma das medidas necessárias a diminuir as sobras decorrentes de aquisição desnecessária ou do não cumprimento do esquema terapêutico proposto (ALVARENGA E NICOLETTI, 2010, p.1).

Então, pode-se dizer que a condição da saúde está relacionada com o contexto socioambiental. Se há um ambiente limpo e sadio para conviver, logo será também propício à saúde, pois conforme Alvarenga e Nicoletti (2010), além da geração de resíduos o descarte doméstico de medicamentos são questões para ser amplamente discutidas e estudadas em nível de saúde pública em que é necessária a responsabilidade coletiva para minimizar o uso excessivo de medicamentos pela população.

No entanto, todos têm o direito de viver em um ambiente saudável, mas para isso é preciso à colaboração do coletivo na preservação e na manutenção dos recursos naturais. Para tanto, as ações essenciais consistem em preservar e cuidar, para alcançar melhores condições de vida. Para que 
esses cuidados com o meio se transformem em ações concretas, é preciso conscientização e mudanças de atitudes.

Portanto, entende-se que, por meio da Educação Ambiental, é possível desenvolver um trabalho de sensibilização e responsabilidade socioambiental a partir da utilização e descarte de medicamentos, em que agregue significados para mudanças atitudinais disseminando essas práticas e propague esses conhecimentos para minimização dos impactos que os medicamentos podem ocasionar ao ambiente.

\section{Metodologia}

O estudo foi desenvolvido no Colégio Estadual Pedro Macedo em Curitiba-Paraná, no período de Maio a Novembro de 2017 com uma amostra constituída de 95 alunos, estudantes do Ensino Médio e Técnico Integrado em Informática e Administração do Colégio Estadual Pedro Macedo em Curitiba PR.

A pesquisa se dá na perspectiva da Pesquisa Participante. Borda (1988) estabeleceu alguns princípios metodológicos da Pesquisa Participante começando com Autenticidade e Compromisso. Autenticidade no sentido de produzir um saber que parte do saber do seu sujeito-objeto, constituído na prática comunitária, demonstrando com transparência e honestidade um compromisso com o saber a ser construído contribuindo com os princípios específicos da Ciência sem a necessidade do disfarce como sujeito de origem da área delimitada para o estudo.

Brandão (1988) compreende a pesquisa participante como um processo compartilhado de desconstrução, construção e reconstrução de conhecimentos na ação transformadora e emancipadora. De forma resumida, a pesquisa participante integra quatro propósitos assim definidos por ele:

a) ela responde de maneira direta à finalidade prática a que se destina, como meio de conhecimento de questões a serem coletivamente trabalhadas; b) ela é um instrumento dialógico de aprendizado partilhado e, portanto, [...] possui organicamente uma vocação educativa e, como tal, politicamente formadora; c) ela participa de processos mais amplos e contínuos de construção progressiva de um saber popular e, no limite, poderia ser um meio a mais na criação de uma ciência popular; d) ela partilha, com a educação popular, de toda uma ampla e complexa trajetória de empoderamento dos movimentos populares e de seus integrantes (BRANDÃO, 2006, p. 46).

A Pesquisa Participante começa por reconhecer que há uma relação estreita entre ciência social e intervenção na realidade com vistas a promover a superação das dificuldades de um determinado grupo social. Isso significa dizer que a Ciência não é o fim em si mesma, mas um instrumento de

revista brasileira educação ambiental 
questionamento sistemático para a construção do conhecimento do cotidiano e do destino humano (MINAYO, 2001; BRANDÃO, 2006).

Por ser crítica-dialética, a Pesquisa Participante busca envolver aquele que pesquisa e aquele que é pesquisado no estudo do problema a ser superado, conhecendo sua causa e construindo coletivamente as possíveis soluções. Para a Pesquisa Participante, os saberes dos indivíduos construídos no cotidiano da vida comunitária são partes importantes no processo de construção do conhecimento (BRANDÃO, 2006).

Como princípio norteador foi realizado apresentação do Projeto de sensibilização e campanha sobre a utilização e descarte de medicamentos. Foi entregue um questionário para se investigar e conhecer a respeito da utilização e descarte de medicamentos visando conhecer o perfil e relação dos estudantes com os medicamentos. Além disso, foi solicitado aos alunos que discutissem com suas famílias sobre os principais medicamentos que são utilizados por eles, bem como as percepções ou práticas com as sobras dos medicamentos e descarte dos mesmos.

Após conhecer o perfil e relação dos estudantes sobre os medicamentos, foi realizado uma Sequência Didática na disciplina de Biologia que pudesse discutir sobre a importância e responsabilidade quanto ao uso dos medicamentos, os perigos da automedicação e os efeitos biológicos e nocivos no organismo a partir de charges, matérias vídeos que retratassem a preocupação com o crescente uso de medicamentos no Brasil.

Posteriormente, o entendimento da compreensão dos efeitos ao metabolismo e fisiologia do nosso corpo foi ensinado e orientados aos alunos participantes sobre a forma correta de descarte dos medicamentos vencidos ou sem uso, alertando-os sobre os perigos de se ter medicamentos em casa e o uso indevido dos mesmos.

Para verificar a eficácia de aplicação do projeto de sensibilização sobre a responsabilidade social quanto à utilização e descarte de medicamentos, foram realizadas rodas de conversa para avaliar de forma exploratória os conceitos aprendidos pelos grupos, e a participação na exposição dos trabalhos para os demais estudantes do Colégio Estadual Pedro Macedo.

A roda de conversa como instrumento de trabalho não foi escolhida sem antes nos depararmos com a necessidade de propiciar à nossa pesquisa um caráter de cientificidade, o que implica caracterizá-la como de natureza qualitativa e determinar sua posição como abordagem legítima da busca do conhecimento científico, posto que esse tipo de pesquisa "[...] é um meio para explorar e para entender o significado que os indivíduos ou os grupos atribuem a um problema social ou humano" (CRESWELL, 2010, p. 26).

Após essa etapa foi criada uma campanha para recolhimento de medicamentos vencidos em parceria com a Secretária Municipal de Saúde no mês de Outubro e Novembro, visando sensibilizar sobre a importância do descarte correto de medicamentos vencidos e orientar quanto quais ações devem ser realizadas quando esses não estiverem mais em uso ou vencidos.

Revbea, São Paulo, V. 13, No 4: 174-189, 2018. 


\section{Resultados e Discussão}

O Projeto de Sensibilização quanto ao uso e descarte correto de medicamentos teve inicio no dia 05 de Maio que é lembrado por ser o Dia Nacional do uso Racional de Medicamentos. A data foi criada para alertar a população quanto os riscos à saúde causados pela automedicação. Tendo como objetivo ressaltar o papel do uso indiscriminado de medicamentos e a automedicação como principais responsáveis pelos altos índices de intoxicação por remédios (BRASIL, 2015). Vê se importante marco pra pesquisa, pois partindo do pressuposto que é um problema emergente quando se retrará o uso indiscriminado de medicamentos e considerando ainda que "a automedicação traz riscos à saúde, pois a ingestão de substâncias de forma inadequada pode causar reações como dependência, intoxicação e até a morte" (BRASIL, 2015).

Após inserir os estudantes na discussão da importância de debater assuntos sobre o uso e descarte de medicamentos, foi aplicado um questionário em que os mesmos puderam responder sobre a relação e concepções sobre o uso de medicamentos, os estudantes participantes de faixa etária entre 14 e 19 anos, sendo $60 \%$ do sexo feminino e $40 \%$ do sexo masculino.

Verificou-se que os estudantes conhecem uma gama de medicamentos utilizados por eles e por suas famílias como apresentado na Figura 1.

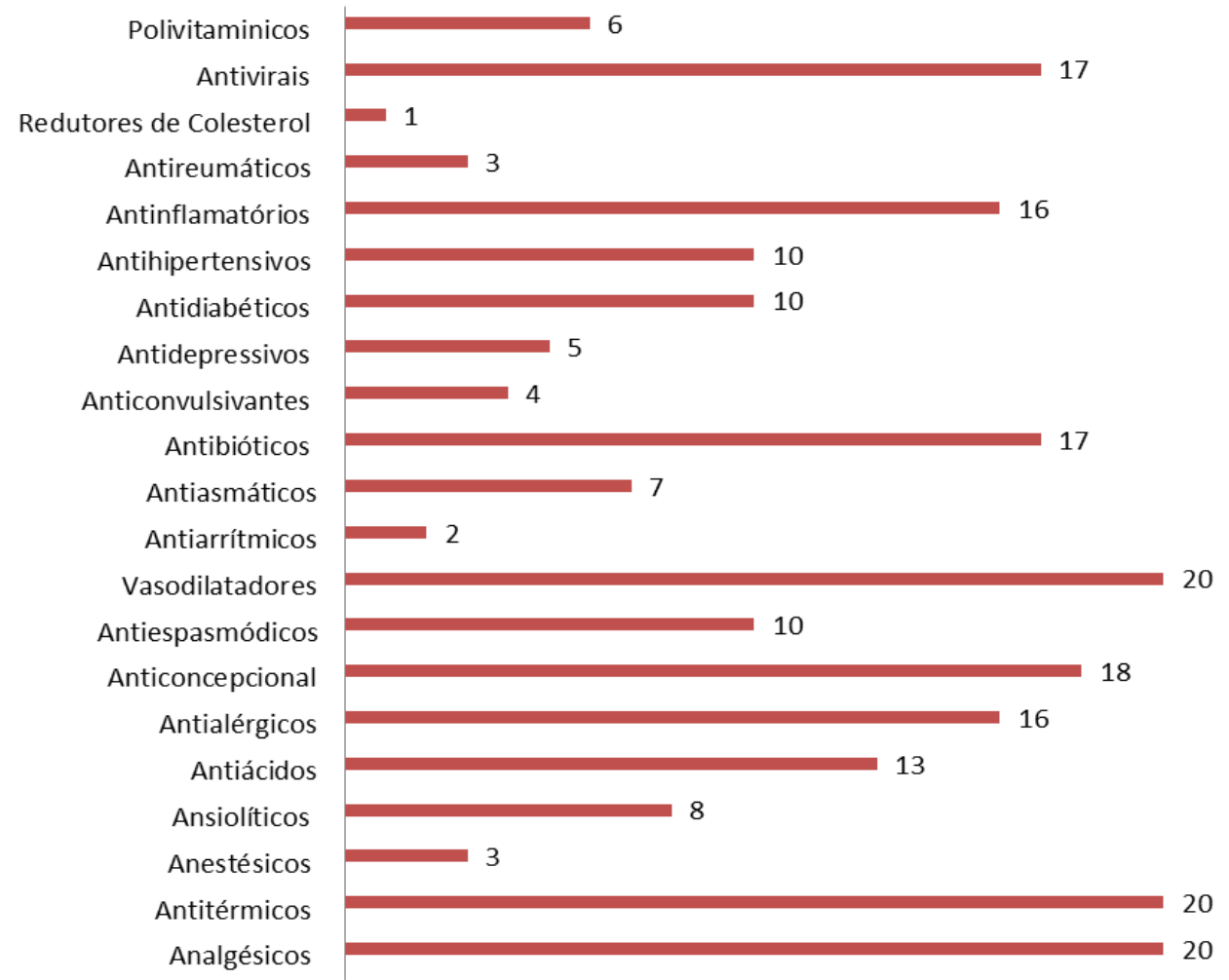

Figura 1: Medicamentos utilizados pelas famílias dos estudantes participantes.

Fonte: Autores.

Revbea, São Paulo, V. 13, № 4: 174-189, 2018.

revista brasileira

educação ambiental 
Observa-se uma variedade de medicamentos utilizados pelos estudantes e suas famílias. Percebe-se que os medicamentos mais utilizados pelos envolvidos são vasodilatadores, antitérmicos, analgésicos, tendo em vista, que a cidade de Curitiba que possui clima instável tendendo mudança de temperatura rapidamente para o frio. Seguido de anticoncepcionais em que as estudantes relatam nas discussões a utilização para controle e regulação da menstruação. Ainda nessa lista se observa a utilização de grande número de antivirais, antibióticos, anti-inflamatórios, antialérgicos, entre outros.

Foi declarado pelos estudantes que grande parte destes medicamentos são comprados com facilidade em farmácias sem indicação ou receitas médicas, prática essa que é destacada pelos estudantes que induz a automedicação. Veem-se esses relatos como uma preocupação constante em que já apontava há muito tempo por Pacheco (1978), Garrafa (1983) e Barros (1995) onde apontavam que pelo menos 35\% dos medicamentos adquiridos no Brasil era feito através de automedicação. Entretanto, se o brasileiro tende a se automedicar, é também porque não encontra disponibilidade dos serviços de saúde mais acessíveis, precisa ficar horas em uma fila e, às vezes, esperar dias e até meses para ser atendido por um médico. O baixo poder aquisitivo da população e a precariedade dos serviços de saúde contrastam com a facilidade de se obter medicamentos, sem pagamento de consulta e sem receita médica em qualquer farmácia, onde, não raro, se encontra o estímulo do balconista interessado em ganhar uma comissão pela venda. Embora o alto consumo e o consumo de medicamentos de forma inadequada tenham sido observados também entre as camadas mais privilegiadas da sociedade, uma vez que essa prática se dá pela herança cultural, de forma instintiva sem qualquer base racional, pela facilidade de acesso, dentre outros.

Relatam que existe uma facilidade muito grande para a aquisição desses fármacos, sem necessidade de receita como já se discute há muito tempo por Pacheco (1978) e Garrafa (1983) quando afirmam que "A automedicação está crescendo e, tornando muitas vezes, abusivo, errôneo e indiscriminado número de prescrições, estão ocorrendo mundialmente". Garrafa (1983) afirma que nenhum fármaco é totalmente inócuo ao organismo, a incidência de efeitos indesejáveis aumenta a cada dia, levando à iatrogenia medicamentosa, causa de elevado número de hospitalização.

De acordo com Medeiros, Moreira e Lopes $(2014$, p.2) grande parte dos,

medicamentos prescritos e adquiridos pela população acabam acumulando-se nas residências, seja de modo intencional ou não. Essas sobras habitualmente são descartadas no lixo comum, ou pelo esgoto, ou são guardadas, formando a chamada 'Farmácia Caseira. 
medicamento e quando é verificada a data de validade e aspecto e, julgado não ter condições, seu descarte acaba ocorrendo diretamente no lixo doméstico, esgoto ou descartado em terrenos baldios.

A partir da compreensão dos estudantes quanto ao uso e reconhecimento de medicamentos, investiga-se qual sua percepção com o uso ou descarte desses componentes medicamentosos como apresentado na Figura 2.

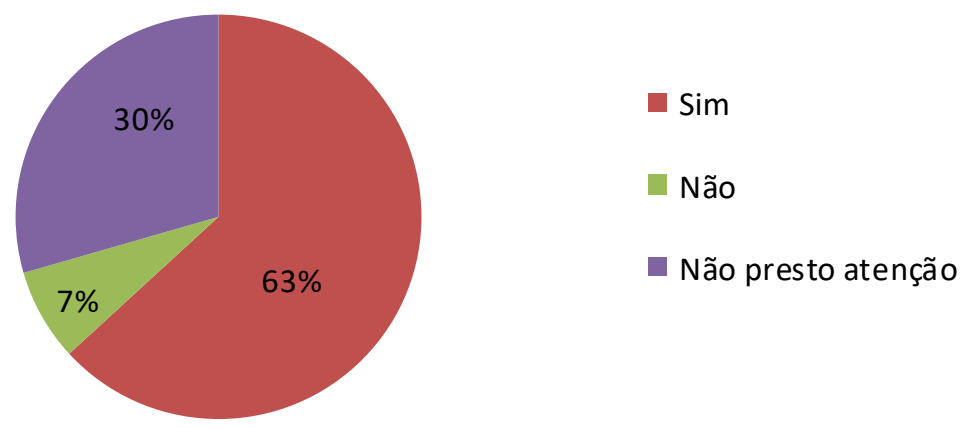

Figura 2: Percepção sobre a sobra de medicamentos após o término do tratamento Fonte: Autores.

Verificou-se ainda que $63 \%$ dos participantes afirmam que percebem a sobra de medicamentos após o término do tratamento e $37 \%$ não prestam atenção.

É discutido constantemente pelo Ministério da Saúde e órgãos competentes sobre os riscos ocasionados tanto pela automedicação assim também como ao meio ambiente. Assim se faz necessário entender à percepção dos estudantes sobre o descarte de medicamentos no ambiente como apresentados na Figura 3 e descritos abaixo com afirmações dos mesmos.
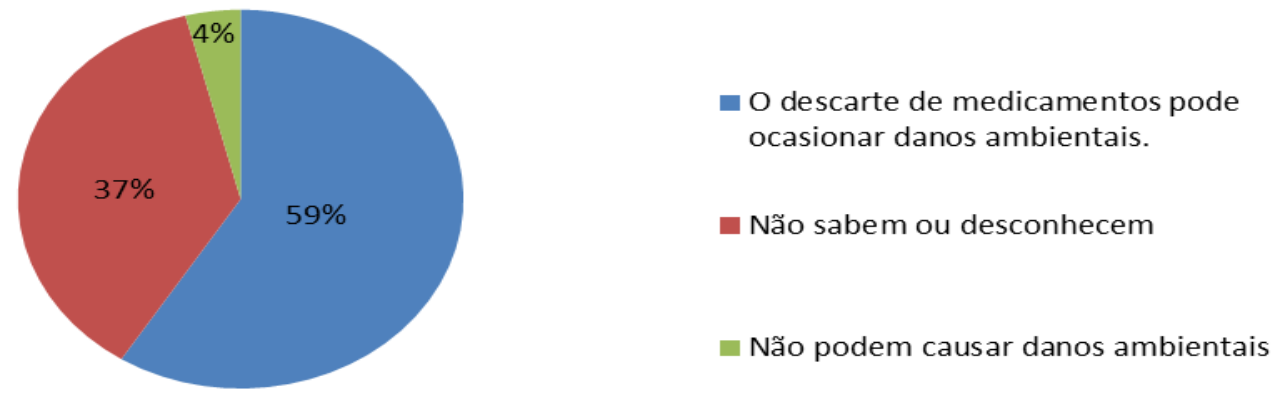

Figura 3: Percepção sobre o descarte de medicamentos pode prejudicar o Meio Ambiente.

Fonte: Autores. 
Ao investigar se os alunos acham que o descarte dos medicamentos pode prejudicar o meio ambiente como observado na Figura 3, obteve-se que $59 \%$ (um pouco mais da metade) sabem que o descarte incorreto de medicamentos pode ocasionar problemas ambientais, seguidos de $37 \%$ que não sabem e $4 \%$ que não acham que os medicamentos podem causar danos ambientais. Dos estudantes que compreendem que 0 descarte de medicamentos pode ocasionar impactos negativos ao ambiente são expressos por eles nos seguintes dizeres "Pode contaminar o Meio ambiente com substâncias químicas e tóxicas", "Intoxicação ou morte de animais", "Intoxicação de pessoas relacionadas ao trato com o lixo", "Contaminação de alimentos desde a cadeia alimentar", "Contaminação do solo".

Segundo Viana et al., (2016, p. 59), "as alterações no ambiente causadas por atividades antrópicas podem ser negativas, destruidoras ou degradadoras dos recursos naturais". O descarte no meio ambiente pode ocasionar inúmeros impactos, um deles é a contaminação de reservas de água limpa que ainda restam. De acordo com Medeiros, Moreira e Lopes (2014, p.3), "os fármacos podem afetar os organismos vivos por rotas metabólicas e moleculares, perturbação hormonal de organismos, causada por contraceptivos e a resistência bacteriana causada por antibióticos", são alguns dos efeitos que podem ocorrem no meio ambiente.

Ainda se investiga com os estudantes sobre a prática com os medicamentos vencidos em suas residências como apresentamos na Figura 4.

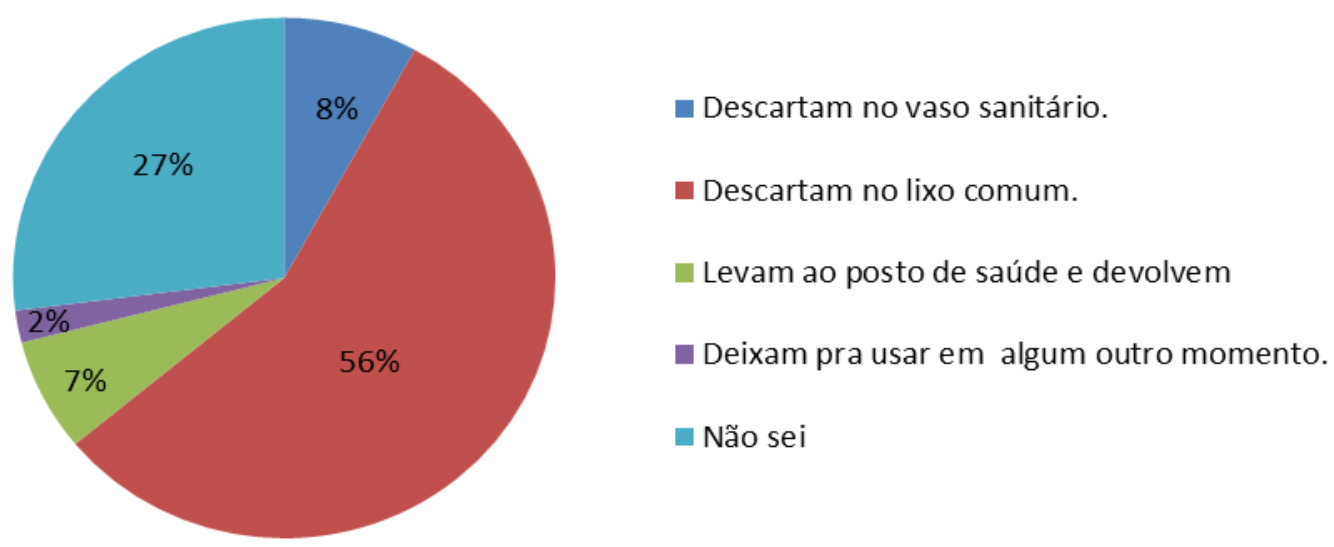

Figura 4: O que é feito com os medicamentos vencidos em sua casa?

Fonte: Autores

Verificou-se que o lixo comum é a principal forma de descarte de medicamentos vencidos (56\% dos participantes), contudo quando colocados no lixo estão trazendo riscos à saúde e ao ambiente, pois de acordo com Cruz, et al., (2017), estudos comprovam que mais de 200 produtos farmacêuticos foram identificados nos sistemas de água doce no mundo, podendo contribuir com o 
desenvolvimento da resistência antimicrobiana. Sendo que apenas um pequeno quantitativo procura dar um destino correto a estes materiais.

Observa-se que $27 \%$ dos estudantes não sabem o que é feito com os medicamentos vencidos, $8 \%$ jogam no vaso sanitário e $7 \%$ entregam a algum órgão de saúde de Curitiba, o que é correto conforme a RDC - Resolução da Diretoria Colegiada 44/09 que institui quais os estabelecimentos que podem participar de coleta coletiva de fármacos vencidos (BRASIL, 2009). Temos que $2 \%$ utilizam os medicamentos mesmo estando com o prazo de validade vencido. Segundo informações do Ministério da Saúde (2014), isso "pode trazer consequências graves à saúde, como reações alérgicas e dependência, além disso, o hábito pode aumentar a resistência de microrganismos e inibir a eficácia dos remédios".

Em muitos municípios brasileiros, os serviços de coleta e disposição final de resíduos sólidos ainda são deficientes. Dados indicam que em 2014, a geração total de resíduos sólidos urbanos (RSU) no Brasil foi de aproximadamente 78,6 milhões de toneladas. Dos 71.260,45 milhões dos RSU coletados, $41,6 \%$ foram destinados a lixões ou aterros controlados (ABRELPE, 2014).

Bueno et al., (2009) afirmam que os resíduos de medicamentos são descartados de diferentes formas. Nos serviços de Saúde, farmácias e distribuidoras, os resíduos devem ser submetidos a tratamento e disposição final específica. Nas residências os medicamentos destinados ao descarte geralmente são depositados no lixo comum ou jogados no lavabo ou no vaso sanitário, o que é incorreto. Percebe-se que a população não sabe onde depositar seus resíduos de medicamentos.

Para sistematizar os resultados apresentou-se números e matérias jornalísticas importantes sobre o uso e descarte de medicamentos no Brasil, além disso, os resultados finais do questionário respondido pelos participantes do projeto e assim possibilitando reflexões e mostrando possíveis ações que pode-se tomar sobre o correto descarte dos medicamentos vencidos ou não utilizados, bem como as implicações do descarte incorreto no meio ambiente.

Os estudantes participantes deste projeto participaram de rodas de conversas, palestra e debates com o intuito de se perceberem como agentes responsáveis pela manutenção do meio onde vivem, tendo que a população abordada, em sua maioria, não pratica hábitos coerentes em relação ao consumo e descarte de medicamentos ou ainda pelo descarte deficitário.

Posteriormente foi realizada a Campanha de recolhimento de medicamentos para destinação final correta como se mostra na Figura 5. 


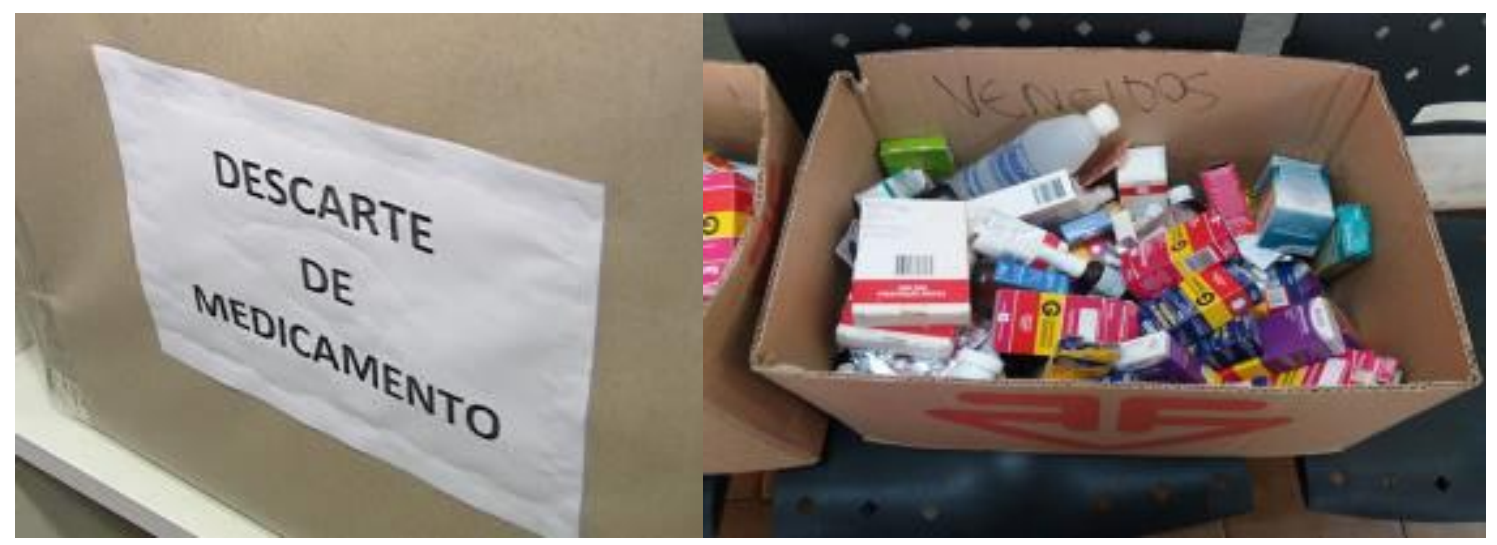

Figura 5: Campanha de Coleta de Medicamentos na escola.

Fonte: Autores.

A campanha de coleta de medicamentos na escola, como ação do Projeto de Sensibilização e Responsabilidade Social foi baseada e fundamentada num projeto para recebimento de medicamentos residenciais realizadas pela Prefeitura de Curitiba, Conselho Regional de Farmácia, Sindicato dos Farmacêuticos e Universidade Federal do Paraná sendo estruturada a partir da Lei Municipal 13.978/12 e Lei Estadual 17.211/12 que serviu de modelo para implantação da logística reversa de medicamentos em todo país e com participação de aproximadamente 50 estabelecimentos ligados ao ramo da saúde (PARANÁ, 2014).

Leff (2001) enfatiza sobre a impossibilidade de resolver os crescentes e complexos problemas ambientais e reverter suas causas sem que ocorra uma mudança radical nos sistemas de conhecimento, dos valores e dos comportamentos gerados pela dinâmica de racionalidade existente, fundada no aspecto econômico do desenvolvimento.

Ao introduzir os estudantes numa Campanha de Responsabilidade Socioambiental na Educação Ambiental no cotidiano escolar, tem-se uma atividade reflexiva, renovadora e transformadora da realidade dentro e fora da sala de aula, pois é um conhecimento que induz a prática e ultrapassa as barreiras físicas da escola, desenvolvendo-se por todos os lugares a que os multiplicadores tenham acesso. Visto que, a falta de conhecimento impede que os estudantes e comunidade escolar realizem práticas como o descarte de medicamentos de forma correta sem agredir ao meio ambiente.

Segundo KRASILCHIK (2005), "as atividades em grupo são mais produtivas do que as individuais, porque estimulam o espírito de cooperação e aumentam a discussão entre os jovens sobre as atividades que estão sendo executadas". Além disso, no envolvimento das primeiras discussões do "senso comum", perpassando o conhecimento cientifico nas diferentes áreas foi constatado que os estudantes reconhecem a importância da contextualização das informações adquiridas e tantas outras que poderiam contribuir para o estudo mais aprofundado sobre o descarte de medicamentos e possibilitar 0 
conhecimento sobre outros temas que não são usualmente discutidos pelas mídias, famílias ou escola.

A Campanha realizada não anula as formas de poder que todo o saber comporta, mas exige a disponibilidade para partilhar o poder, isto é, partilhar um saber e um poder que se tem consciência de não ser proprietário. Trata-se de não ocultar o seu próprio saber/poder, mas, ao contrário, torná-lo discursivo e acessível à compreensão de outros. (GATTÁS; FUREGATO, 2006).

\section{Considerações Finais}

A partir da realização deste trabalho de Responsabilidade socioambiental utilizando a Educação Ambiental a partir da perspectiva da utilização e descarte de medicamentos, foi possível verificar que os estudantes e suas respectivas famílias mantêm hábitos inadequados quanto ao uso de medicamentos, pois a maioria desconhece a forma correta de descarte de medicamentos, recorrem à estocagem de remédios e os usa sem a devida prescrição médica, muitas vezes colocando em risco a própria saúde, ou de seus familiares e ao meio ambiente. Além disso, o descarte é algo extremamente preocupante, visto que uma parcela da população o faz em lixo comum, tendo como destino o contato com o solo e com a água, causando a sua contaminação.

Desta forma, é notável a necessidade de intervenções constantes, que contribuam principalmente para a conscientização da correta utilização e descarte de medicamentos, pois apenas divulgar informações não é suficiente. É preciso propor ações que possibilitem às pessoas assumirem o seu papel de cidadãos responsáveis pelo meio em que vivem. Sendo assim, as ações deste projeto tiveram um importante papel na sensibilização e conscientização das pessoas pertencentes à comunidade escolar, além de proporcionar importantes reflexões a respeito dos nossos atos enquanto seres que dependem dos recursos naturais para bem viver.

Pelos resultados alcançados, ainda é necessário um alerta contínuo, propagar e fomentar constantes campanhas tendo a escola como uma instituição de grande influência na vida dos alunos, além de cumprir sua função social possibilita aos estudantes a sensibilização e respeito com o meio ambiente, promovendo a Educação Ambiental e evidenciando suas potencialidades, suscitando a adoção de posturas pessoais e comportamentos sociais construtivos, colaborando para a construção de um ambiente saudável.

\section{Referências}

ABRELPE. Associação Brasileira De Empresas de Limpeza Pública e resíduos Especiais. Panorama dos resíduos sólidos no Brasil (2014). Disponível em: < http://www.abrelpe.org.br/Panorama/panorama2014.pdf > Acesso em: 10 Dez 2017. 
ALIGLERI, L.; ALIGLERI, L.A; KRUKLIANSKAS, I. Gestão socioambiental: responsabilidade e sustentabilidade do negócio. São Paulo: Atlas, 2009.

ALVARENGA, L. S. V.; NICOLETTI, M. A. Descarte doméstico de medicamentos e algumas considerações sobre o impacto ambiental decorrente. Revista Saúde, UNG, 2010, Vol.4(3), pp.34-39. Acesso em: 16 Jan 2017. Disponível em: <https://dialnet.unirioja.es/servlet/articulo?codigo= 3651641>.

BRASIL. Lei no 12.305, de 2 de agosto de 2010. Institui a Política Nacional de Resíduos Sólidos; altera a Lei no 9.605, de 12 de fevereiro de 1998; e dá outras providências. Brasília, [2010]. Disponível em: <http://www.planalto.gov.br /ccivil 03/ ato2007-2010/2010/lei//12305.htm>. Acesso em: 05 Dez 2017.

BORRELY, S.I. Contaminação das águas por resíduos de medicamentos: ênfase ao cloridrato de fluoxetina. São Paulo-SP: [s.n.], 2012. 8 p. Disponível em: <http://www.saocamilo-sp.br/pdf/mundo saude/97/03.pdf >. Acesso em: 05 Dez. 2017.

BUENO, C.S.; WEBER, D.; OLIVEIRA, K.R. Farmácia Caseira e Descarte de Medicamentos no Bairro Luiz Fogliatto do Município de ljuí - RS. Revista de Ciências Farmacêuticas Básica e Aplicada. V. 30, n. 2, p. 75-82, 2009.

CRUZ, M. J. B. et al. Descarte de medicamentos em municípios do Vale do Jequitinhonha, Minas Gerais, Brasil. Revista Visa em Debate: sociedade, ciência e tecnologia, v.5, n.1, pp.84-90, 2017.

DIAS, G. F. Educação ambiental: princípios e práticas. 9 ed. São Paulo: Gaia, 2004.

EICKHOFF P; HEINECK I; SEIXAS L.J. Gerenciamento e destinação final de medicamentos: uma discussão sobre o problema. Rev. Bras. Farm; 90(1): 648. 2009.

FALQUETO, E.; KLIGERMAN, D. C.; ASSUMPÇÃO, R. F. Como realizar o correto descarte de resíduos de medicamentos? Revista Ciência \& Saúde Coletiva, v. 15, p. 3283- 3293, 2010.

GARRAFA, V. Contra o monopólio da saúde: temas para debate. Rio de Janeiro, Editora Achiami, 1983.

GARCIA, B.G. et al. Responsabilidade social das empresas: a contribuição das universidades. São Paulo: Fundação Peirópolis, 2002.

GASPARINI, J.C.; GASPARINI, A.R.; FRIGIERI, M.C. Estudo do descarte de medicamentos consciência ambiental no município de Catanduva-SP. Rev. Ciência \& Tecnologia, v. 2, n. 1, p. 38-51, 2011.

GATTÁS, M.L.B.; FUREGATO, A.R.F. Interdisciplinaridade: uma contextualização. São Paulo/SP, 2006.

JACOBI, P. Educação ambiental, cidadania e sustentabilidade. Cadernos de Pesquisa, São Paulo, n. 118, p. 189-205, mar. 2003. 
KRASILCHIK, M. Práticas de ensino de biologia. 4. ed. Editora da Universidade de São Paulo, p. 127. 2005.

LEFF, E. Epistemologia ambiental. São Paulo: Cortez, 2001.

LIMA, D.R. Manual de farmacologia clínica, terapêutico e toxicologia. Rio de Janeiro: Medsi, v. 1. 2003.

MEDEIROS, M.S.G., MOREIRA, L.M.F., LOPES, C.C.G. O. Descarte de medicamentos: programas de recolhimento e novos desafios. Rev. Ciênc. Farm. Básica Apl., v. 35, n.4, pp.651-662, 2014.

PACHECO, M.V.A. A máfia dos remédios. Rio de Janeiro, Ed. Civilização Brasileira 1978. (Coleção Retrato do Brasil).

PARANA, Projeto Piloto para descarte de resíduos de medicamentos domiciliares no município de Curitiba: "Medicamento não é lixo: Descarte no lugar certo" Curitiba, 2014. Disponível em: < https://crfpr.org.br/uploads/noticia/13799/Projeto para Descarte de Resduos de Medic amentos Domiciliares no municipio de Curitiba.pdf > Acesso em 01 Mai. 2017.

VIANA, B.A.S.; VIANA, S.C.S.; VIANA, K.M.S. Educação ambiental e resíduos sólidos: descarte de medicamentos, uma questão de saúde pública. Rev. Geogr. Acadêmica, v.10, n.2: pp.56-66 (xii. 2016). 